\section{Malaria Strains Resistant to 4-amino-quinoline Drugs}

SIR,-In a letter referring to malaria strains showing resistance to the 4-aminoquinoline group of drugs (24 July, p. 229) it was stated that in some instances crossresistance has been found to extend to all other available synthetic antimalarial compounds. In such circumstances it would be necessary to fall back on quinine for treatment of a malarial attack.

I would point out that this would not necessarily constitute a retrograde step. It is not generally appreciated that the development of most of the synthetic antimalarial drugs was inspired by the fact that Germany was cut off from all sources of cinchona during the first world war, and not by defective action of quinine.

In point of fact quinine, though not suitable for prophylaxis, is a most effective weapon for the treatment of a malarial attack, and in Plasmodium falciparum infections it is capable of effecting radical cure. This applies particularly to strains occurring in tropical Africa, which is the source of the majority of malarial infections encountered in Great Britain.-I am, etc.,

Public Health Laboratory Service,

G. Covell.

Malaria Reference Laboratory,

Horton Hospital,

Epsom, Surrey.

\section{Varicose Veins in Pregnancy}

SIR,-One statement in Mr. Harold Dodd's letter (31 July, p. 304) disturbed me. He states that "stripping, which is fashionable," should be "relegated to the limbo of irrational operations."

I was less disturbed, however, when reading the rest of the letter, and the description of the study of Zulus with " tooth-paste stools" which cause Mr. Dodd to state in his letter that the eating of one to four tablespoonfuls of bran daily would lessen the incidence of varicose veins in pregnancy.

This made me realize that the statement regarding stripping need not necessarily be taken seriously, and I do hope for the benefit of the enormous number of sufferers that it is indeed disregarded.-I am, etc.,

London W.1.

$$
\text { R. Rowden Foote. }
$$

\section{A New Protozoon}

SIR,-In your issue of 19 June (p. 1602) Professor P. C. C. Garnham publishes a highly critical review of my book, $A$ New Protozoon : Its Relation to Malignant and Other Diseases. I feel that some of his remarks are less than fair, and I should welcome the opportunity of replying to several points he raises. Firstly, I did not, as he suggests, make any claim to a curative effect of 4-aminoquinolines on reticuloses, cancer, or premalignant diseases, but merely recorded the effects of administering these drugs in such conditions and the fact that they may cause complete regression in premalignant conditions-and also in reticuloses lasting now up to seven years or more.

Secondly, Professor Garnham states that the frequency of remissions in the various diseases makes a cause-and-effect relationship unproved. Some of the patients were in extremis suffering from reticuloses with complete radiological "blackout" of onehalf of the chest, or carcinomatosis and unconsciousness due to cerebral metastatic tumours with pleural effusion. Their response to treatment was almost immediate and rapid, and in these circumstances could surely not be attributed to natural remissions in the illness. Furthermore, in the book I gave references to independent confirmatory results by Japanese workers of the results of such treatment. Other reviewers have not cast doubt on this aspect of the work.

Thirdly, Professor Garnham tends to dismiss the organism as "amorphous fragments." Against this are the identical appearances, pigmentation, and size of the organism in all conditions from which it was recovered. Some of the microphotographs of the delicate hollow spheres with fenestrated circumferences (Figs. 17-19) closely resemble other protozoa, such as Noctiluca miliaris, and the veined forms (Figs. 15-16) stages in the life history of Myxomycetes (see Wenyon's Protozoology, 1926). These could hardly be artificial fragments. As stated in the book, slides of the organism were shown to a number of Professor Garnham's fellow protozoologists, who agreed on its organismal nature. He might be interested to know that the finding of the organism has already been confirmed in other countries of the world.-I am, etc.,

London W.1.

R. WYBURN-MASON.

\section{Diagnosis of Hysteria}

SIR,-Dr. Robert Thompson's letter (24 July, p. 234) contains statements and premises which I for one cannot accept without clarification. He wrote, "the confusion in the diagnosis and treatment of hysteria lies... in a failure to differentiate two types of anxiety - the anxiety which is based on depression and the anxiety which is based purely on suggestion."

For years many psychiatrists have diagnosed anxiety with depression and depression with anxiety as separate conditions, placing the primary syndrome first. The hypothesis on which they base these diagnoses is clearly that depression and anxiety are separate entities and that these frequently co-exist. Hence the failure to bring about a sustained improvement if E.C.T. or antidepressants are mistakenly given for a primary anxiety state with secondary depression. There would appear to be no valid reason for using the term anxiety neurosis (or state) for depression with anxiety as suggested by Dr. Thompson, even if he does not believe that an anxiety state can exist as a separate entity uncomplicated by either hysteria or depression. He did not say this, but his suggestion infers it.

I believe a great deficiency in definition exists. Anxiety is frequently given as a symptom of depression, particularly in advertising circulars for antidepressant drugs. After 25 years' psychiatric experience I am now certain that whenever anxiety symptoms are present they are part of a separate syndrome and never a symptom of depression. Perhaps attacks of agitation are mistaken for anxiety symptoms by some therapists who believe they are hearing described or witnessing an acute anxiety attack.
In my view attacks of agitation and acute anxiety attacks are distinguishable. Agitation is defined as a behaviour pattern, always occurring in response to ideas of disaster, and it is psychotic. On the other hand, anxiety consists of a chain of autonomic physiological changes set in motion by fear (the connexion between the fear and the symptoms usually being unrealized by the patient), and it is neurotic. Secondary phobias arising from autonomic changes in anxiety (e.g., heart disease from tachycardia) are not idea's of disaster, phobias having a basis in fact not delusion.

But if Dr. Thompson believes I am splitting hairs and that anxiety occurs in depression as a symptom, he is in good company-Mayer-Gross, Slater, and Roth (Textbook of Clinical Psychiatry (1955 edition, p. 199 , para. 2 ; page 205 , para. 1), although p. 200, para. 4, does perhaps tend to bear out my theory regarding the delusional basis for agitation.

Dr. Thompson has done a service in reminding us of Pavlov's definition of hysteria. If psychiatry is to become an exact science clear definition remains the essential. The hardest illness of all to define is hysteria. Dr. Thompson suggests that the fainting by a medical student faced with the operating theatre is a good example. I would say that it was much more likely to be an autonomic response due to anxiety and that the mild hypochondriasis of his other examples are due either to depression or anxiety, certainly not hysteria. If fainting were hysterical the subject would go on fainting at intervals after being removed from the scene of his conflict. Surely hysterical symptoms always persist beyond the moments of impact with the precipitating factors ?

It is of paramount importance that the depressions, anxiety, hysteria, and obsessional states be clearly defined, and that it is accepted that admixtures of any or all can occur in the same patient at the same time, and when they occur together are separate syndromes requiring additional treatment. It is because of the prevailing inexactitude of definition in psychiatry that one is bedevilled by reams of descriptive case notes written by juniors which do not conclude with a diagnosis, a situation which Mayer-Gross himself deplored and spoke about at least once at an R.M.P.A. meeting.-I am, etc.,

$$
\begin{aligned}
& \text { Garlands Hospital, W. V. A. ERSKINE. } \\
& \text { Carlisle. }
\end{aligned}
$$

\section{Infection in Schools}

SIR,-I am interested in the conflicting views expressed on the value of school exclusion in eliminating the spread of Sonne dysentery contained in the article by $\mathrm{Dr}$. A. B. Christie (19 June, p. 1597) and the letter from Dr. G. M. O'Donnell (24 July, p. 235), both in this journal. Sonne dysentery is admittedly usually a mild disease but is always a nuisance and sometimes serious, while relapses and/or second attacks are of frequent occurrence. (Last week a child in one of my districts was admitted to hospital with convulsions and pyrexia of $106^{\circ} \mathrm{F}$. $\left(41.1^{\circ}\right.$ C.).)

My own view is that school exclusion has an important part to play as a method of reducing the weight of infection, particularly 
in the younger age groups, where susceptibility is greater and personal hygiene more on the " ground floor." Environmental circumstances also need to be taken into account, since there are clearly differences between an urban school with good hand-washing and sanitary facilities and an overcrowded rural school, where, as is sometimes the case, hand-washing facilities still leave a very great deal to be desired. In my view these are the kind of factors an M.O.H. must take into account if he is to do his job. (In the case of dysentery he can only advise the head teacher to exclude a child as the law stands at present.)

With regard to bacteriological investigation, while two negatives certainly are not indicative of absolute freedom from infection they are a useful yardstick for practicable purposes. As to the drug treatment, in recent years I have found neomycin (because of its relative insolubility and freedom from side-effects) to be the most useful for routine purposes, while in refractory cases and in the carrier condition Colomycin (colistin) in my own limited experience has never let me down, provided heavy dosage is employed, unfortunately an expensive procedure at present.

In the winter of 1962-3, whilst medical officer of health of Buxton (population 19,400 ), there were 88 cases notified to me over a period of five months. One of the cases was a school meals server, and there were several instances of food handlers who were either infected or close contacts. The epidemic was treated vigorously, largely because of the importance of eradicating an excremental disease in a holiday town Children in junior age groups were excluded from school as far as possible, and general practitioners were asked to consider the use of neomycin in small doses prophylactically in the case of family contacts. The winter 1962-3 was extremely cold and $20 \%$ of the service water pipes in the town were frozen for many weeks, while frozen soil pipes too made conditions very unpleasant for a very long time. I cannot believe that the epidemic would have "burned itself out" in the complete way it did under these circumstances before the end of March without active intervention.-I am, etc.,

Marlborough, Wilts.

F. D. F. Steede.

\section{Give Us the Tools}

SIR,-The letter you published from $\mathrm{Dr}$. A. G. Scott Langley (24 July, p. 237) suggesting an adequate blanket capitation fee and the cessation of haggling over petty expenses was most refreshing. Give us the tools (in this case the cash) and we will get on with the job, including continuing to provide, like our predecessors, a 24-hour cover every day of the year. We can make our own arrangements for time off and we can use every up-to-date device to make our practices efficient. Moreover, we can return to a more paternal attitude within our practices and stop the abuses which we hear so much about.

For this ideal state of affairs it is necessary to reach agreement with the Minister (or will it have to be with the Review Body ?) on three items only.

(1) What is a general practitioner worth in terms of net income (taking into account all the usual things, such as years of training and responsibility of his work and so on), if he works a 45-hour week ? That is to say, compare him with the majority of the professions and assess him on the income scale for the same hours.

(2) How many patients can a practitioner look after and only work 45 hours a week? The agreed scale for this number of patients should be paid to him, and if he is energetic, efficient, and skilful enough to look after twice the number, let him be paid accordingly.

(3) Agree on a reasonable figure for expenses and pay it as a lump sum, but let it be subject to the doctor providing proof of actually acquiring these expenses. This expense factor must include the cost of one secretary-receptionist for each doctor and a figure for his premises, whether he owns them or rents them, as well as the usual expenses, such as heating, lighting, telephone, cleaning, and motor-car.

The virtue of this reduction of the interminable discussions to three factors only is that the public, through the press, can be presented with figures that they understand. If, for example, it is stated that the country does not think its doctors worth $£ 2,750$ net, for a 45 -hour week, and that it does not think that a doctor should have enough money to employ a secretary-receptionist and provide modern premises, then the public will understand why we would have to withdraw from the Service.

Let us try to get a few elementary figures agreed and then leave us to run our practices as we only know is the best way to run them. Group-practice loans, finance corporations, petty concessions over certification, extra pay for night calls, and out-of-hours calls-the whole lot of niggly petty rules, regulations, and concessions can be thrown overboard. Give us the tools (in this case the cash) and we will get on with the job.-I am, etc.,

Cosham, Portsmouth. V. H. Martindale.

\section{Discouraging Attendance for Trivial Complaints}

SIR,-After the Swansea meeting I was angry and upset at the decision to try to put a monetary deterrent between doctor and patient. Apart from the political ineptitude of this manœuvre, it would not work in the intended way. An unreasonable, demanding patient, having paid his fee, would not only feel he had a right to what he sought but also that he had paid for it, and this would make him more difficult than ever to refuse. It is certain that no fee which could reasonably be charged would deter such a patient ; and any fee would operate more harshly on the needy than on others.

Another type of deterrent, much in evidence in some practices, is the crowded waiting-room. This penalizes the frail and those whose time is valuable.

What is the alternative? Some sort of filter is required, the point about a filter (as opposed to a deterrent) being that it passes some particles freely and stops others. It is not generally realized that an appointment system acts in this way. Provided that an intelligent secretary-receptionist is employed, a fair degree of selection becomes possible, and urgent cases can be given priority. A reasonable amount of trouble has to be taken by the patient in order to see the doctor, and this is brought home to the patient by the system and makes him feel that seeing the doctor is an important bit of business. Rich and poor are equally controlled, and the treat- ment of those in medical need can be prompt, and without any sort of queue or discomfort.

Further advantages of the system (apart from the obvious ones to the patients) are that the doctors can control the work flow, diverting special cases to clinics at which a nurse may be present, and shifting the load from heavy days to slack ones. Much clerical and other simple duties can be delegated to the staff which are necessary to run such a system.

Using these methods, I find that my list patients averaged 3.1 doctor-patient meetings during the past year (including visits to their homes), which is nicely below the national average, although my list has more than twice the national average of over-65:s, and $4.1 \%$ of it are over-80s. I do not seem to see many trivial complainers, and suppose that the system must put them off.-I am, etc.,

Paignton, Devon.

J. F. Burdon.

\section{Help for Resigning Doctors}

SIR,-The Times for 4 August carries an article headed "City Seeks to Replace 13 N.H.S. Doctors. Rubicon neared in Birmingham." Now I do not agree with their action, but I do not practise in or near Birmingham. Indeed, I do not approve of any withdrawal from the N.H.S. and my resignation is not in the hands of the Guild. None the less, these colleagues feel strongly and what they have done should have our sympathy if not our approval.

They may be right, and I believe that we should see to it that for a time, say three to six months, they should have the financial support of the rest of us so that they may fight their battle free from the pinch of the purse. I was most interested to notice that their lists were mostly around 2,500. It must be accepted as a fact not only that living in urban areas has drawbacks not felt by those of us who live in more pleasant surroundings, but also that where the sole source of income is the capitation fee without additions from midwifery, clinic, or hospital work, or dispensing, especially where there is no private income, then a list of 2,500 is not enough to give a decent standard of living.

I for one would be very happy to contribute to any centrally managed fund which will see that they and their families will not suffer, and that they will be encouraged to stay in this country though not necessarily in Birmingham. The solution to the problem of the future of general practice in this country lies with the inexorable law of supply and demand.-I am, etc.,

Shipton-under-Wychwood, GoRdon Scotr. Oxford.

\section{Report of College of General Practitioners}

SIR,-After having read the College of General Practitioners' report on general practice I must record my disagreement with many of its conclusions. Rather do I take the attitude expressed in your leading article (24 July, p. 182). I am a member of the College, of its Welsh Faculty Board, and of the Welsh Faculty Postgraduate Education Committee. I am also a participant in 